\title{
Práticas docentes na Saúde: contribuições para uma reflexão a partir de Carl Rogers
}

\author{
Eliana Silva Cassimiro de Araújo \\ Vânia Maria de Oliveira Vieira
}

\begin{abstract}
Resumo
O trabalho do profissional da área da saúde depende da qualidade técnica e da interação pessoal que institui. Sua formação deve oferecer subsídios para que o egresso utilize características humanistas ao exercer sua prática profissional. Esta pesquisa, realizada com o aporte teórico de Carl Rogers, objetivou verificar a presença da concepção humanista nas práticas educativas dos professores da área da saúde de uma universidade em MG. Optou-se por uma abordagem qualitativa, com pesquisa bibliográfica e de campo. A coleta dos dados procedeu-se por meio de um questionário aplicado a 41 docentes de 05 cursos da saúde. De forma singela, verificou-se a presença de propostas humanistas: nos Projetos Pedagógicos dos cursos, que defendem um ensino centrado no estudante com professores facilitadores e aprendizagem significativa; e nas práticas pedagógicas docentes, delineadas na forma como o professor articula o conteúdo, avalia, planeja, interage com os alunos e utiliza as estratégias de ensino.
\end{abstract}

Palavras-chave: Formação dos profissionais da saúde, educação, Humanismo.

\section{Teaching practices in health area: contributions for reflexions from Carl Rogers}

\begin{abstract}
The work of professional in the health area depends on the technical quality and on establishing personal interaction. His/her training should provide subsidies so that egress from this area can make use of humanist features on exercising his/her professional practice. Supported by the theoretical contribution of Carl Rogers, we aim at verifying the presence of humanist conception in the educational practices of teachers of the health area in a university in MG. We opted for a qualitative approach, with bibliographical and field research. Data collection was conducted through a questionnaire administered to 41 teachers from 5 health courses. We could observe the scarce presence of humanist proposals: the Pedagogical Projects of the courses, which advocate a student-centered teaching with faculty facilitators and meaningful learning. In teaching pedagogical practices outlined in the way teacher organize the content, how he/she evaluates, plans, interacts with students and makes use of teaching strategies.
\end{abstract}

Keywords: Health professionals education, education, Humanism.

\section{Prácticas docentes en la salud: contribuciones para una reflexión a partir de Carl Rogers}

\section{Resumen}

El trabajo del profesional del área de salud depende de la calidad técnica y del establecimiento de interacción personal. La formación del egreso debe ofrecer subsidios para que utilice características humanistas al ejercer su práctica profesional. Esta investigación, realizada con o aporte teórico de Carl Rogers, tuvo el objetivo de verificar la presencia de la concepción humanista en las prácticas educativas de los profesores del área da salud de una universidad en Minas Gerais. Se optó por un abordaje cualitativo con investigación bibliográfica y de campo. La recolección de datos se realizó por medio de un cuestionario aplicado a 41 docentes de 05 cursos da salud. De forma simple se verificó la presencia de propuestas humanistas: en los Proyectos Pedagógicos de los cursos que defienden enseñanza centrada en el estudiante con profesores facilitadores y aprendizaje significativa; y en las prácticas pedagógicas docentes delineadas por la forma como el profesor articula el contenido, evalúa, planea, interactúa con los alumnos y utiliza las estrategias de enseñanza.

Palabras Clave: concepción humanista de educación; formación de profesores da salud; prácticas educativas. 


\section{Introdução}

O profissional da área da saúde deve reconhecer que sua profissão é uma forma de contribuição social e para tal deve ter autonomia, no sentido de aplicar seus conhecimentos na busca de soluções de problemas clínicos individuais e comunitários. Assim, deve estabelecer significativas relações interpessoais com as pessoas que atende. Seu trabalho depende de dois fatores: a qualidade técnica e a interação pessoal. Por isso, é importante que se forme um egresso com características humanistas.

Carl Ramson Rogers, psicólogo norte-americano, destaca-se como pioneiro no desenvolvimento da psicologia humanista e traz grandes contribuições para o campo da educação. Sua teoria enfatiza as relações humanas, visualiza a existência do sujeito como um processo contínuo de desenvolvimento e busca resgatar o respeito pelo ser humano.

De acordo com Rogers, a aprendizagem em uma sala de aula depende de um ambiente facilitador, em que o professor deve assumir atitudes humanistas frente aos seus alunos e durante a realização de suas práticas docentes. Para esse autor, "a didática centrada na pessoa enfatiza o professor e o aluno como pessoas e sua relação existe em um clima de respeito mútuo, onde cabe ao professor, basicamente, dar ao aluno condições favoráveis para desenvolver seu potencial intelectual e afetivo" (Rogers, 2001, p. 52).

É comum encontrar propostas humanistas de educação em leis, pareceres, projetos pedagógicos, planos de ensino e outros documentos que norteiam a educação. A LDB - Lei de Diretrizes e Bases da Educação Nacional 9.394/96, a Constituição da República Federativa do Brasil e o Relatório para a UNESCO da Comissão Internacional sobre Educação para o século XXI são alguns exemplos de como as ideias humanistas de Rogers estão presentes nas propostas de educação.

Ciente da importância das contribuições rogerianas para a educação, presentes em diversas propostas educacionais, e considerando-se inquietações que incomodam a muitos quanto à relação professor/aluno e à influência dessa relação na formação humanista do egresso da área da saúde, optou-se por realizar este estudo investigativo.

\section{Contribuições de Carl Rogers para a educação na saúde: algumas considerações teóricas}

A filosofia humanista é um movimento que pode ser definido por meio de três pressupostos de base que são descritos nas obras de Carl Rogers. O primeiro tem como principal premissa uma visão do homem como um "organismo digno de confiança" (Rogers, 1974, p. 16). O segundo e terceiro pressupostos abordam a prática fenomenológica que privilegia a experiência subjetiva da pessoa, surgindo como consequência o conhecimento do outro a partir de seus referenciais e a forma de relacionamento que se constitui como um encontro entre pessoas (Rogers, 1974).
Apesar de, na perspectiva de Rogers, essas três atitudes fazerem parte de um conjunto que deve estar integrado na pessoa do professor, elas serão aqui descritas separadamente para melhor explicitar o quadro conceitual do autor.

A primeira - aceitação positiva incondicional -, de acordo com Rogers (1974), se expressa na capacidade de aceitar a pessoa do aluno, os seus sentimentos, as suas opiniões, com valor próprio, e confiar nele sem o julgar. É uma confiança no organismo humano e uma crença nas suas capacidades enquanto pessoa.

A segunda - compreensão empática -, conforme Rogers (1974), é um processo que significa a capacidade de penetrar no universo do outro, sem julgamento, tomando consciência dos seus sentimentos, respeitando o ritmo de descoberta de si mesmo, fazendo com que o outro se sinta aceito e compreendido como pessoa na sua totalidade a partir do seu quadro de referência interno.

A terceira - a congruência - refere-se à autenticidade do facilitador, que Rogers (1974) considerou como a mais básica e que designa como a capacidade de o facilitador mostrar-se como uma pessoa real, sem máscara nem fachada na relação com o aluno. Tal qualidade contrasta com a atitude, comum no ensino tradicional, em que "o professor é um ator, representando um papel e não uma pessoa autêntica" (Rogers, 1974, p. 128). A proposta de Rogers traduz-se numa relação de pessoa para pessoa, e não de um papel de professor para um papel de aluno.

Rogers (1974) afirma que, se essas atitudes, consideradas como condições facilitadoras, estiverem presentes na relação, a pessoa entra num processo de aceitação de si própria e dos seus sentimentos, tornando-se a pessoa que deseja ser, mais flexível nas suas percepções e mais capaz de aceitar os outros. Ao modificar suas características pessoais básicas de modo construtivo, a pessoa adota um comportamento mais ajustado à sua realidade.

Para o autor, das três condições facilitadoras descritas, a mais importante é a autenticidade, pois se refere a uma atitude com relação a si próprio e não com o outro, uma vez que só se pode dizer o que se passa em relação a nós mesmos.

De acordo com a proposta de Rogers, é importante que o professor tente encontrar o fio condutor que orienta os alunos e, se necessário, reformular conhecimentos e o método de ensiná-los. O principal escopo dessa proposta é o abandono da passividade pelo aluno, substituindo-a por um papel ativo, de intervenção no seu próprio processo de aprendizagem, e, a partir daí, a aprendizagem centra-se no aluno.

Rogers entende ser absolutamente essencial que desde cedo os jovens aprendam a se posicionarem dentro de problemas complexos, identificando os prós e contras de cada solução, até que encontrem uma decisão bem formada, pois tal habilidade é um objetivo primário da educação que não pode ser atingido através de opiniões dogmáticas.

As atitudes enunciadas permitem não só o desenvolvimento intelectual do aluno, mas o seu crescimento enquanto pessoa total, promovendo a aprendizagem significativa e a interiorização do processo de aprender, e cabe ao docente desenvolver formas que facilitem a criação da liberdade no 
ambiente de ensino-aprendizagem. O autor elenca algumas práticas educativas humanistas como, por exemplo, trabaIho com problemas percebidos como reais, fornecimento de recursos, uso de contratos, ensino por parte de seus pares, divisão em grupos, instrução programada como aprendizagem experiencial ${ }^{1}$, grupo de encontro e autoavaliação.

Exemplos dessas práticas pedagógicas nos cursos da saúde são as aulas práticas pré-clínicas, nas quais os alunos manuseiam manequins para aprender os procedimentos clínicos; as atividades dos estágios nas unidades básicas de saúde, que permitem ao aluno a interação com o outro; e as ações educativas realizadas pelos acadêmicos nas escolas para a promoção à saúde. Em todos esses exemplos, o aluno é o centro do processo de aprendizagem e o professor é o facilitador que orienta as atividades. Essas atividades têm como objetivos promover aprendizagem significativa e a internalização destas por parte dos alunos.

Entende-se que a proposta de Aprendizagem Centrada no Aluno tem como premissa principal permitir ao discente uma participação ativa no seu processo de aprendizagem, no seu processo de crescimento pessoal, e tem como pressuposto a ideia de que essa cooperação melhora a eficácia da ação docente. Nesse caso específico, a docência em cursos da saúde.

Acredita-se que a qualidade do processo de aprendizagem passa, por um lado, pela construção de uma relação pedagógica com base na aceitação e compreensão da pessoa do aluno e, por outro, pelo pressuposto de que o aluno contém em si potencialidades para aprender e, como tal, terá motivação para "o fazer" - o papel do professor facilitador será o de estimular e desenvolver as potencialidades do aluno e simultaneamente manter a motivação necessária ao seu crescimento e desenvolvimento pessoal.

\section{O ensino na área da saúde e a formação docente}

De acordo com Feuerwerker (1998), a Lei de Diretrizes e Bases da Educação Nacional (LDB), ao apontar novas configurações para os padrões curriculares da educação na área da saúde, indica a necessidade de uma reestruturação dos cursos de graduação e de mudanças paradigmáticas para os professores que nela atuam. Nesse sentido, para discutir as práticas pedagógicas e a formação continuada desses professores, faz-se necessário refletir sobre uma base conceitual e metodológica capaz de subsidiar os cursos da saúde para a formação de professores críticos que possam atuar tanto na educação como na prática e sobretudo na promoção de mudanças em qualquer um desses espaços.

1 Segundo Kolb (1984), citado por Pimentel (2007, p. 160), aprendizagem experiencial é um "processo por onde o conhecimento é criado através da transformação da experiência". Essa definição enfatiza que o conhecimento é um processo de transformação, sendo continuamente criado e recriado. A aprendizagem transforma a experiência tanto no seu caráter objetivo como no subjetivo. Para compreendermos aprendizagem, é necessário compreendermos a natureza do desenvolvimento e vice-versa (1984, p. 38).
Já no início do seu curso de graduação, o aluno, por meio da disciplina Anatomia Humana, realiza estudos em cadáveres e, muitas vezes, depara-se com situações de óbito. A partir de então, o convívio com a dor, o sofrimento e o óbito ou sua possibilidade são diários, e ele ainda não apresenta em sua formação a necessária preparação para enfrentar essas situações geradoras de angústias. Caso o professor não esteja preparado para atuar com aceitação incondicional e compreensão empática, o aluno poderá apresentar variados mecanismos defensivos que podem incorporar-se à personalidade do futuro profissional de saúde. As ansiedades dos alunos devem ser consideradas, uma vez que, ao serem experimentadas, revelam sentimentos e dificuldades na sua prática educativa.

Ora, sabe-se que, após um período de estudo teórico e em laboratórios, o aluno depara com o seu cliente. Estudou a anatomia, fisiologia, patologia humana e farmacologia clínica, e agora tem diante de si um ser humano com quem precisa relacionar-se para tratar. De acordo com Martins (2004), esse é um momento de autoavaliação, ele irá testar e verificar o que aprendeu até o momento ao longo do curso. Por outro lado, a condição humana do cliente, que aqui é alguém que sofre, reclama e muitas vezes não informa e exige soluções imediatas para seu problema, coloca o aluno diante da necessidade de desenvolver seu talento para cuidar desse ser humano, o que exige desde o saber ouvir até a prescrição de um tratamento.

A orientação do professor, segundo Meleiro (1999), deve favorecer a autoestima do aluno para o manejo de novas situações; a troca aberta de ideias com os professores e com os colegas com relação às situações pessoais relacionadas ao desempenho profissional; a não ocultação da ansiedade e incerteza diante de atitudes defensivas, que influenciarão o raciocínio do diagnóstico e tratamento do cliente; a dinâmica interna de grupo com vistas a tornar o aluno receptivo e não ameaçador.

Martins (2004) aponta que os conceitos de sujeito, responsabilidade, respeito, verdade, consciência e autonomia, presentes no cotidiano das práticas da saúde, devem ser interiorizados pelo aluno para que possam nortear a sua vida profissional, constituindo-se no alicerce de uma formação e prática humanistas.

De que modo se pode pensar numa formação humanista a partir das práticas pedagógicas dos professores? A forma como o professor articula o conteúdo, avalia, realiza o planejamento, interage com os alunos e utiliza as estratégias de ensino pode contribuir para uma formação humanista de seus alunos?

E a formação desses professores? Que contribuições autores como Roberto e Cunha, Rogers, Tardiff podem-nos trazer para o acirrado debate que tem cercado o tema da formação docente e, nesse caso, trazê-lo para a formação de professores do campo da saúde?

Em geral, os professores que atuam nos cursos da área da saúde são profissionais que se formaram como bacharéis em cursos da área e que demonstram domínio de conteúdo da área específica em que lecionam. Não apre- 
sentam, portanto, formação pedagógica, que se faz por meio de suas práticas em sala de aula e de formação continuada de professores. Uma minoria apresenta licenciatura na área de ciências biológicas, atuando, portanto, em disciplinas curriculares da área básica da saúde, formada pela morfologia, fisiologia e patologia. Os bacharelados não apresentam, em sua formação de graduação, os aspectos pedagógicos; por outro lado, os docentes têm a experiência clínica e bagagem teórica. Já os licenciados não apresentam essa experiência.

Ribeiro e Cunha (2010), referindo-se à formação de professores universitários para a saúde, registram alguns estudos que têm contribuído com reflexões nessa área. Citam Pedrosa (conforme citado por Ribeiro \& Cunha, 2010), que, ao estudar docentes do curso de nutrição, confirmou que eles se reconhecem pela sua profissão de origem, sem, entretanto, valorizar o exercício do magistério. Para as autoras, isso denota que o poder e o prestígio vêm do campo específico e não do saber pedagógico da docência. Selbach e Riegel (conforme citado por Ribeiro \& Cunha, 2010), preocupados com as práticas pedagógicas nos cursos de Enfermagens, apontam as contradições vividas entre a formação pós-graduada dos docentes e os desafios que encontram no magistério. Urtiaga (conforme citado por Ribeiro \& Cunha, 2010), ao analisar as representações de estudantes do curso de Medicina, verificou a necessidade de trabalhar melhor essas questões junto aos professores, para que eles possam ter oportunidades de refletirem sobre suas práticas de ensino, formação e questões relacionadas à ética do profissional da saúde.

Ribeiro e Cunha (2010) reconhecem que esses estudos têm oferecido importantes dados para reflexões, no entanto, ainda há poucos resultados que provoquem efetivas mudanças.

Para Tardiff (2002), a primeira característica a ser assinalada a respeito do trabalho docente é que ele lida com indivíduos. O professor não pode desconsiderar as diferenças individuais dos seus alunos, visto que são os sujeitos que aprendem e não os grupos. As situações de trabalho docente não levam à solução de problemas gerais do grupo, e sim individuais, muitas vezes complexos e marcados pela instabilidade, sendo obstáculos às generalizações, às receitas técnicas e às técnicas definidas de maneira definitiva.

O professor da área da saúde precisa estar aberto às mudanças em sua forma de trabalhar, estar atento às metodologias ativas e às novas práticas pedagógicas, que não mais incluem o simples repasse de informação/conteúdo. É necessário priorizar a troca de construções de conhecimentos de cada um, a escuta e o acolhimento nas relações, para que os egressos da área da saúde possam comungar com uma prática profissional humanista.

\section{Objetivos, materiais e métodos}

O estudo teve como objetivos: verificar, a partir das ideias de Carl Rogers, a presença da concepção humanista nas práticas educativas dos professores da área da saúde de uma universidade em Minas Gerais. Como objetivos específicos: identificar na teoria humanista de Carl Rogers as contribuições para uma formação e prática docente humanista na área da saúde; analisar o pensamento dos professores da área da saúde, a partir da sua prática docente, sobre a concepção humanista da educação; e oportunizar para os docentes da área da saúde reflexões/decisões sobre as práticas pedagógicas para a formação de egressos com perfil humanista.

Para a realização do presente estudo, contou-se com o aporte teórico de Carl Rogers, com intenção de possibilitar espaços de reflexão e decisões acerca da relação professor/ aluno e posterior profissional/cliente.

Nesta pesquisa, entendeu-se por "práticas pedagógicas docentes" a forma como o professor articula o conteúdo, avalia, realiza o planejamento, interage com os alunos e utiliza as estratégias de ensino.

Optou-se por uma abordagem qualitativa, contando com pesquisa bibliográfica e de campo. Como fonte de estudo para a pesquisa bibliográfica, utilizaram-se algumas obras de Carl Rogers, a saber: "Sobre o poder pessoal" (2001a), "A terapia centrada no paciente" (1974), " Tornar-se pessoa" (2001b), "Liberdade para aprender" (1973) e " Um jeito de ser" (1983), no intuito de destacar as principais contribuições desse autor para o campo da educação, em especial para a formação de egressos da área da saúde.

Para a pesquisa de campo, a coleta dos dados foi realizada por meio da aplicação de um questionário estruturado, além de revisões bibliográficas referentes ao PDI - Plano de Desenvolvimento Institucional - e dos Projetos Pedagógicos dos cursos da instituição pesquisada, com a finalidade de relacionar o discurso institucional com as práticas dos docentes.

Constituíram o campo de investigação 05 (cinco) cursos da área da saúde - Odontologia, Medicina, Fisioterapia, Biomedicina e Enfermagem. A escolha deles procedeu-se pelo fato de contarem com maior número de docentes no quadro da Universidade. Participaram ao todo 41 (quarenta e um) professores, sendo que a maioria leciona em mais de um curso, o que nos possibilitou computar um número maior de participantes em cada curso.

Assim, verificou-se com esses sujeitos, a partir das ideias de Carl Rogers, a presença da concepção humanista em suas práticas educativas e a importância dessas práticas para a formação de egressos na área da saúde.

\section{Resultados}

\section{Plano de Desenvolvimento Institucional e Projetos Pedagógicos}

A partir da leitura do Plano de Desenvolvimento Institucional (PDI) da instituição pesquisada e dos Projetos Pedagógicos dos cursos, foi possível verificar algumas 
características humanistas presentes nas práticas pedagógicas institucionais, que incluem a flexibilização curricular, realizada através do PIAC (Programa Institucional de Atividades Complementares), e a presença de componentes curriculares semipresenciais e não presenciais nos cursos, que garantem a autonomia intelectual do aluno.

Os Projetos Pedagógicos dos cursos pesquisados evidenciam, em diversos momentos, estar em consonância com o Plano de Desenvolvimento Institucional.

Os perfis para a formação dos alunos, que foram descritos nos documentos, também parecem demonstrar características humanistas, uma vez que todos eles visam à formação de profissionais com consciência crítica e autonomia intelectual.

A palavra humanista foi inclusive citada literalmente na definição dos referidos perfis em todos os documentos.

No contexto da avaliação da aprendizagem, embora apenas um curso tenha citado a autoavaliação como instrumento avaliativo, que é uma abordagem rogeriana, podem-se perceber algumas características humanistas presentes em três cursos, tais como: ser um processo contínuo, permanente e de acompanhamento; e apresentar-se de maneira cooperativa e prazerosa, ampla, abrangente e multiaxial, transparente, qualitativa e orientadora.

Cumpre observar que o Projeto Pedagógico de um dos cursos pesquisados apresentou significativa tendência humanista, com as características analisadas citadas acima e defendendo um ensino centrado no estudante com professores facilitadores e a evidente aprendizagem experiencial ou significativa, características visivelmente rogerianas.

A prática pedagógica de tutoria, defendida por Rogers, também aparece no documento de um dos cursos analisados.

\section{Características humanistas nas práticas pedagógicas dos professores da saúde}

Além das análises documentais realizadas sobre o Plano de Desenvolvimento Institucional e dos Projetos Pedagógicos dos cursos pesquisados, investigou-se também, por meio de um questionário com questões abertas e fechadas, a partir das ideias de Carl Rogers, a presença da concepção humanista nas práticas educativas dos professores.

O questionário continha também algumas questões referentes ao delineamento do perfil dos sujeitos. Em síntese, os dados demonstram que: a maior representatividade de docentes encontra-se na faixa etária de 31 a 35 anos, prevalecendo o sexo feminino e estado civil casado, seguido de solteiro; $85 \%$ possuem uma religião, com predomínio da católica, seguida da espírita; alguns docentes apresentam mais de uma graduação; todos os sujeitos apresentam alguma pós-graduação, em diferentes áreas do conhecimento, com predomínio das áreas biológicas e da saúde; a maioria dos sujeitos apresenta pouco tempo de experiência docente; $55 \%$ não exercem outra atividade trabalhista além da docência; a maioria, $85 \%$, realiza leitura de livros além dos que se referem à disciplina que ministram; $76 \%$ nunca leram ou estudaram a teoria de Carl Rogers.

As questões seguintes objetivaram identificar situações relacionadas a práticas pedagógicas dos docentes pesquisados.

Solicitamos aos professores que escrevessem 03 (três) palavras que lhes viessem à mente ao ler a frase "prática docente humanista" e depois assinalassem a mais importante justificando em seguida sua resposta. O objetivo foi identificar o significado do termo apresentado para o grupo pesquisado. As palavras compreensão, empatia, respeito, ensino, conhecimento, interação, responsabilidade, aluno, acolhimento e dedicação parecem representar, ainda que de forma tênue, o que pensam os professores quando leem a expressão "prática pedagógica humanista".

As justificativas dessas palavras foram analisadas com o subsídio de Bardin (1977), resultando em 4 categorias: Compreensão empática, uma prática pedagógica humanista; O aluno como centro do processo de aprendizagem; Aprendizagem significativa; Compreensão e autenticidade do facilitador da aprendizagem. Pode-se inferir que o professor, para os sujeitos pesquisados, necessita ser compreensivo empático e que estabeleça interações com os alunos a partir do respeito, da responsabilidade, do acolhimento e da dedicação para o ensino e o conhecimento.

No que se refere à confecção do plano de ensino, de acordo com os dados, infere-se que a maioria dos professores tende a seguir uma abordagem humanista. Embora apenas 14 docentes considerem as sugestões dos próprios alunos para realização do plano de ensino, 30 (trinta), ou seja, a maioria, observam a relevância dos conteúdos para a formação dos alunos.

No tocante ao momento de pensar e articular o conteúdo com a formação do aluno, embora 03 (três) docentes demonstrem não considerar importante, 38 (trinta e oito) apresentam características humanistas em suas práticas pedagógicas, uma vez que preocupam em como e onde os alunos irão aplicar o que aprenderam.

Quanto à realização do planejamento, apesar de 20 (vinte) docentes afirmarem preocupação com o cumprimento dos conteúdos previstos, o que pode parecer uma atitude tradicional, 32 (trinta e dois) observam a relevância dos conteúdos, seguidos de 28 (vinte e oito) que escolhem as estratégias de ensino de acordo com os alunos e o conteúdo.

No tocante às estratégias utilizadas para a condução das aulas, observa-se que as consideradas humanistas ficam em segundo plano - adotam prioritariamente as aulas expositivas e dialogadas com recursos audiovisuais. Não estamos aqui afirmando que esse tipo de aula não possibilita uma prática pedagógica humanista, mas, nesse caso, parece-nos contrapor com os resultados até então apresentados. Ao usar apenas aulas expositivas com recursos audiovisuais, o professor é visto como o centro do processo de aprendizagem e não o aluno, como sugere Rogers. Parece-nos ainda que a adoção preferencialmente por esse tipo de estratégia deixa a desejar outras que propiciam a internalização do aprendizado para o aluno. 
Quanto ao item "ensinar e aprender", a análise dos dados coletados evidencia que a maioria dos sujeitos (30 professores) compreende esse termo a partir de uma perspectiva humanista, enquanto 15 adotam uma abordagem cognitivista, 06, teoria tradicional e 01, a teoria comportamental de Skinner.

No que diz respeito às estratégias e/ou instrumentos que utilizam para avaliar os alunos, observa-se que a maioria não utiliza estratégias humanistas para a avaliação: 34 professores responderam que utilizam avaliações com questões dissertativas; seguidos de 30 que utilizam avaliações com questões objetivas; 26, atividades em grupo; 23 , seminários; e 14 observam o comportamento do aluno. Em momento algum aparece a utilização ou o incentivo à prática da autoavaliação - o que é recomendado por Carl Rogers.

No tocante à interação professor/aluno dentro e fora do contexto da sala de aula, os dados apontaram que 20 docentes apresentam boa interação com seus alunos; 10 apresentam uma relação estritamente profissional; 07 parecem se expressar compreensivamente, com aceitação incondicional; e apenas 02 demonstram não apresentar interação positiva com os alunos.

Por fim, pediu-se aos sujeitos que pensassem sobre suas práticas docentes e relatassem situações que pudessem exemplificar as condições básicas para o ensinar e o aprender segundo Rogers: autenticidade; consideração positiva e incondicional; e compreensão empática. Esses termos foram explicados em um pequeno texto antecedendo a pergunta, com a intenção de precaver-se caso algum sujeito não tivesse conhecimento sobre eles.

De modo geral, os professores apresentaram poucas situações vivenciadas em sala de aula que pudessem ser relacionadas com as condições básicas para ensinar e aprender. Alguns entendem a autenticidade dentro do significado rogeriano de ser transparente, verdadeiro e apresentar-se sem máscaras, no entanto outros a confundem com a exposição do conteúdo com clareza. Quanto à consideração positiva incondicional, alguns a entendem como aceitação do outro tal qual ele é, porém vários confundem o termo com motivação do aluno. Em relação à compreensão empática, todos os sujeitos a entendem como compreender o outro colocando-se no lugar dele. Percebe-se também um número significativo de abstenções, pois 15 (quinze) sujeitos não responderam a essa questão. Algumas hipóteses podem ser consideradas, uma delas é a pouca compreensão dos termos indicados - mesmo tendo sido explicados anteriormente, parece que não apresentam familiaridade com eles, o que pode ter causado dificuldades para relacioná-los com as práticas pedagógicas.

\section{Considerações finais}

A partir da leitura do Plano de Desenvolvimento Institucional (PDI) da instituição e dos Projetos Pedagógicos dos cursos, foram verificadas algumas características humanistas presentes nas práticas pedagógicas institucionais, que incluem a flexibilização curricular, realizada através do PIAC (Programa Institucional de Atividades Complementares), e a presença de componentes curriculares semipresenciais e não presenciais nos cursos, que estimulam a autonomia intelectual do aluno.

A flexibilização curricular faz parte da abordagem de Carl Rogers, uma vez que garante a individualização curricular. Os alunos apresentam currículos diferentes mesmo tendo se formado em uma mesma turma do mesmo curso. Além dos componentes curriculares obrigatórios, realizam atividades extracurriculares que passam a constituir o histórico escolar de acordo com seus interesses profissionais futuros. Essa prática pode promover a individualização do sujeito como profissional e direciona-o em sua futura prática. $\mathrm{O}$ aluno tem a liberdade de escolha no que se refere às atividades que irá realizar.

A presença de componentes curriculares presenciais e não presenciais é uma prática pedagógica que estimula a autonomia intelectual do aluno. Ele aprende a estudar sozinho, ou seja, passa a ser o responsável direto pelo seu aprendizado, com liberdade e flexibilidade para gerir seus horários de estudo. Nessa prática, encontramos sempre a presença de um preceptor, que cumpre a função de facilitador de aprendizagem.

Tanto o PDI quanto os Projetos Pedagógicos dos cursos descrevem os perfis para a formação dos alunos a partir de propostas humanistas, o que parece demonstrar a busca de uma formação profissional com consciência crítica e autonomia intelectual. Constata-se isso principalmente quando se observa que a palavra "humanista" foi citada literalmente na definição dos referidos perfis em todos os documentos.

No tocante aos perfis para a formação dos alunos, verifica-se que visam à formação de profissionais com consciência crítica e autonomia intelectual, o que denota a visão de um egresso com características humanistas, apto à tomada de decisões, a realizar diagnósticos, a manusear instrumentais de acordo com a sua formação, além de aptidão para sua formação continuada com vistas ao aprimoramento futuro em sua profissão.

Características da avaliação da aprendizagem tais como ser um processo contínuo, permanente e de acompanhamento, descritas em todos os documentos, parecem evidenciar intenções da aplicabilidade de práticas pedagógicas humanistas. Porém, apenas um curso citou a autoavaliação como instrumento avaliativo, que é a prática defendida por Rogers. Podemos inferir desses dados que, apesar da intenção, ainda existe uma fragilidade em consolidar as práticas humanistas no que se refere aos instrumentos avaliativos.

Cumpre observar que um dos Projetos Pedagógicos pesquisados demonstra uma significativa tendência humanista ao apontar características referentes ao perfil e à avaliação de aprendizagem, condizentes com as ideias de Rogers para a formação de seus egressos. Esse projeto ainda defende um ensino centrado no estudante com professores facilitadores e a evidente aprendizagem experiencial ou significativa. 
A prática pedagógica de tutoria, defendida por Rogers, também aparece no documento de um dos cursos. Ela constitui uma prática pedagógica que visa à orientação dos alunos ao longo de sua formação universitária e promove um suporte de acompanhamento pelo professor tutor no que diz respeito ao processo de ensino e aprendizagem.

Embora a maioria dos professores pesquisados seja jovem - encontra-se na faixa etária de 25 (vinte e cinco) a 35 (trinta e cinco) anos -, todos já cursaram uma pós-graduação. No entanto, grande parte apresenta pouco tempo de experiência docente, entre 02 (dois) e 05 (cinco) anos. Evidenciam-se, dessa maneira, professores jovens e com pouca experiência docente, o que parece demonstrar certa fragilidade no tocante à abordagem humanista, tendo em vista que, para Carl Rogers, a autoridade do professor reside em sua experiência docente e domínio do conteúdo que leciona.

Outro dado relevante que também deve ser destacado é o fato de a formação dos professores ocorrer predominantemente nas áreas biológicas e da saúde. Essa informação corrobora outro dado apontado - a questão de a maioria dos professores não ter, durante a formação acadêmica, lido ou estudado sobre a teoria de Carl Rogers. Além disso, nas leituras realizadas por eles, não estão incluídas as referentes à psicologia, à educação e à filosofia.

Provavelmente, em consequência disso, quanto ao entendimento dos professores sobre a "prática pedagógica humanista", verificamos que não foi possível identificar claramente uma representação significativa desse termo. É importante ressaltar que essa lacuna ocorre até mesmo nos cursos de psicologia, onde a teoria humanista é pouco estudada.

Constata-se que os professores apresentam uma modesta tendência humanista no que diz respeito à elaboração de planos de ensino, à realização do planejamento das aulas, à articulação de conteúdos para a formação do aluno e ao que consideram como o ensinar e aprender. No que diz respeito às estratégias para a condução das aulas e para o processo avaliativo, adotam prioritariamente as práticas tradicionais, com aulas expositivas e avaliações dissertativas ou objetivas. Percebe-se, dessa forma, que o discurso dos professores é humanista, no entanto o ato pedagógico que perdura ainda é o da educação tradicional. Levando-se em consideração que a filosofia existencialista considera o indivíduo como a soma de suas ações, pode-se inferir que os professores pesquisados proporcionam ainda uma precária prática pedagógica humanista.

Assim, a partir dessas inferências, pôde-se tecer algumas considerações acerca da presença da concepção humanista nas práticas educativas dos professores da área da saúde de uma universidade em MG.

Para isso, apontamos as contribuições de Carl Rogers para formação de egressos da área da saúde e verificamos, embora de uma forma singela, a presença de propostas humanistas nos Projetos Pedagógicos dos cursos e nas práticas pedagógicas docentes, delineadas na forma como o professor articula o conteúdo, como avalia, como re- aliza o planejamento, como interage com os alunos e como utiliza as estratégias de ensino.

Esperamos que este trabalho possa promover reflexões no campo da educação, principalmente entre os educadores da área da saúde, para que nossos egressos tenham uma formação acadêmica com vistas a cumprir seus papéis como cidadãos e profissionais responsáveis e seguros de seus atos na sociedade em que estão inseridos.

Dada a importância desse estudo e considerando os resultados aqui apontados, sugerimos algumas ações para que a formação do egresso na área da saúde tenha características humanistas. Pensamos ser oportuno que as instituições formadoras repensem os currículos dos cursos de formação na área da saúde, de modo que eles possam contemplar questões ligadas à formação humanista. Da mesma forma, repensar também os cursos de formação continuada para os docentes, hoje mais conhecidos como "desenvolvimento profissional", entendido por Marcelo Garcia (1999, p. 144) como "o conjunto de processos e estratégias que facilitam a reflexão dos professores sobre a sua prática”, e, dessa forma, possibilitá-los a se familiarizarem com conceitos e práticas relacionados à formação humanista.

\section{Referências}

Bardin, L. (1977). Análise de conteúdo. Lisboa: Ed. 70.

Feuerwerker, L. C. M. (1998). Mudanças na educação médica e residência médica no brasil. Interface - Comunicação, saúde, educação, 2(3)

Garcia, M. C. (1999). Formação de professores - para uma mudança educativa. Porto, Portugal: Porto Editora.

Martins, M. C. F. N. (2004). Humanização das relações assistenciais: a formação do profissional de saúde (3a ed.). São Paulo: Casa do Psicólogo.

Meleiro, A. M. A. S. (1999). O médico como paciente. São Paulo: Lemos Editorial.

Pimentel, A. (2007). A teoria da aprendizagem experiencial como alicerce de estudos sobre desenvolvimento profissional. Estudos de psicologia, 159-168.

Ribeiro, M. L., \& Cunha, M. I. (2010). Trajetórias da docência universitária em programas de pós-graduação em saúde coletiva. Em M. I. Cunha (Org.), Trajetórias e lugares de formação da docência universitária: da perspectiva individual ao espaço institucional. Araraquara, SP: Junqueira \& Marin editores.

Rogers, C. (1973). Liberdade para aprender (2a ed.). Belo horizonte: Interlivros.

Rogers, C. (1974). A terapia centrada no paciente. Lisboa: Moraes Editores. 
Rogers, C. (1983). Um jeito de ser (3a ed.). São Paulo: Editora Pedagógica e Universitária.

Rogers, C. (2001a). Sobre o poder pessoal (4a ed.). São Paulo: Martins Fontes.

Rogers, C. (2001b). Tornar-se pessoa (4a ed.). São Paulo: Martins Fontes.

Tardiff, M. (2002). Saberes docentes. Formação profissional. Petrópolis, RJ: Vozes.
Universidade de Uberaba. (1997). Plano de desenvolvimento institucional. Uberaba, MG.

Universidade de Uberaba. (1997). Projeto pedagógico dos cursos de biomedicina, enfermagem, fisioterapia, medicina e odontologia. Uberaba, MG.

Recebido em: 10/01/2012

Reformulado em: 12/03/2012

Aprovado em: 19/04/2012

\section{Sobre as autoras}

Eliana Silva Cassimiro de Araújo (eliana.cassimiro@terra.com.br)

Universidade de Uberaba - UNIUBE - Uberaba - MG - Brasil

Mestre em Educação pela UNIUBE

Endereço residencial: Rua Maestro Alberto Frateschi, 40 - Bairro: Estados Unidos - CEP: 8081160 - Uberaba - MG

Vânia Maria de Oliveira Vieira (vaniacamila@uol.com.br)

Universidade de Uberaba - UNIUBE - Uberaba - MG - Brasil

Doutora em Psicologia da Educação pela PUC/SP

Endereço residencial: Rua Vigário Silva 745 apto 1103 - Centro - CEP: 38022-190 - Uberaba - MG 